\title{
Sonographic Assessment of Optic Nerve Sheath Diameter and Its Correlation with CSF Opening Pressure in Patients with Idiopathic Intracranial Hypertension
}

\author{
Jobin Mathew ${ }^{1}$, Srikumar B ${ }^{2 *}$, Dileep $\mathrm{R}^{3}$
}

${ }^{1}$ Senior Resident, Department of Neurology, Government Medical College, Thiruvananthapuram, Kerala 695011, India

${ }^{2}$ Professor, Department of Neurology, Government Medical College, Thiruvananthapuram, Kerala 695011, India

${ }^{3}$ Assistant Professor, Department of Neurology, Government Medical College, Thiruvananthapuram, Kerala 695011, India

DOI: $10.36347 /$ sjams.2020.v08i11.043

| Received: 30.09.2020 | Accepted: 16.10.2020 | Published: 29.11.2020

*Corresponding author: Srikumar B

\section{Abstract}

Original Research Article

Background: Idiopathic Intracranial Hypertension (IIH) has an incidence of about 2.2/100000 in general population. Optic Nerve Sheath Diameter (ONSD) is found to be high in raised intracranial tension. Studies on ONSD and IIH are limited. ONSD measurement is non-invasive compared to spinal manometry. So, measuring the ONSD can be used as a screening tool on outpatient basis in patients suspected to have IIH and also for follow up of patient on treatment. Methods: The aim of this study was to correlate cerebrospinal fluid (CSF) opening pressure with optic nerve sheath diameter measured using ultrasonogram in patients with idiopathic intracranial hypertension and to study changes in optic nerve sheath diameter before Lumbar puncture (LP), one hour after, and 6 months after CSF drainage in patients with idiopathic intracranial hypertension. IIH was diagnosed with modified Dandy's criteria. A total of 30 cases and 30 controls were included in the study. Trans orbital sonography was done to assess the optic nerve sheath diameter (ONSD) before and after lumbar puncture. CSF opening pressure was measured. ONSD was done in 30 matched controls. Follow up ONSD was done at 6 months. Results: Mean age was 31 years in cases and 30 years in controls. Mean BMI was 35 in cases and 25.5 in controls. Mean ONSD was $6.46 \pm 0.67 \mathrm{~mm}$ in cases, $4.87 \pm 0.26 \mathrm{~mm}$ in control $(\mathrm{p}<0.001)$. A positive correlation was found between CSF opening pressure and pre- LP mean ONSD ( $\mathrm{r}=0.584$, $\mathrm{p}<0.001)$. Post LP mean ONSD was $5.83 \pm 0.48 \mathrm{~mm}$ ( $\mathrm{p}<0.001)$. Optimum ONSD for detecting IIH was $5.42 \mathrm{~mm}$ with sensitivity and specificity of $96.7 \%$. Mean ONSD at 6 months follow up was $5.18 \pm 0.58 \mathrm{~mm}$ (p<0.001). Conclusions: ONSD measurement can be used as an additional tool to identify patients with IIH. It can also be used to follow up patients on treatment.

Keywords: Idiopathic Intracranial Hypertension, Optic Nerve Sheath Diameter, cerebrospinal fluid.

Copyright (C) 2020 The Author(s): This is an open-access article distributed under the terms of the Creative Commons Attribution 4.0 International License (CC BY-NC 4.0) which permits unrestricted use, distribution, and reproduction in any medium for non-commercial use provided the original author and source are credited.

\section{INTRODUCTION}

Idiopathic intracranial hypertension is characterized by the presence of pathologically elevated intracranial pressure (ICP), no dilatation of ventricles, intracranial mass lesion and other computed tomography (CT) scan / Magnetic Resonance Imaging (MRI) findings as cause for raised ICP, and normal composition of cerebrospinal fluid (CSF). Intracranial hypertension (IH) occurs in multiple neurological diseases with raised intracranial pressure (ICP) that can lead to a secondary brain damage. It is a disease affecting young adult female of child bearing age group. It is more common in obese persons. It was previously known as benign intracranial hypertension. However, it was later found that if untreated, IIH patients can develop significant visual impairment and blindness. So, it is essential to identify and treat the disease.
Sonographic assessment of the optic nerve sheath diameter (ONSD) has been found to be a reliable test to diagnose raised ICP in neurocritical patients [1, 2]. However, its use to diagnose idiopathic intracranial hypertension $(\mathrm{IIH})$ comes from limited clinical case reports [3, 4]. The optic nerve is a tubular structure having $5 \mathrm{~cm}$ in length. Its intraorbital segment can be measured sonographically. Histologically it is having the same meningeal layers as the brain [5]. The optic nerve is a hypoechoic linear structure located inside the optic nerve sheath. Subarachnoid space is situated between the sheath and the optic nerve. Optic nerve sheath diameter is increased in intracranial hypertension as increased pressure is transmitted throughout the subarachnoid space to the optic nerve head [6, 7]. Therefore, the presence of an increased ONSD is an 
indirect sign of IH because changes in ICP have a direct influence on the peri optic subarachnoid space diameter. However, cut off values of ONSD have not yet been defined to predict raised intracranial pressure. So to identify raised intracranial pressure and to diagnose IIH, lumbar puncture and CSF manometry is essential. Repeated lumbar punctures are required in patients having IIH on treatment to know the response to treatment. Noninvasive methods like ONSD will be an ideal alternative to CSF manometry especially for follow up of patients having IIH. This study was conducted to find out the correlation between CSF pressure and ONSD and to find out the optimal ONSD value above which we can confirm the diagnosis of raised CSF pressure and IIH.

\section{Aims And OBJEctives}

Aim

To correlate CSF opening pressure with optic nerve sheath diameter (ONSD) in patients with idiopathic intracranial hypertension and to study changes in ONSD before and after CSF drainage. To find the optimal ONSD cut off which will predict IIH.

\section{Primary Objective}

1. To measure optic nerve sheath diameter in patients with Idiopathic intracranial hypertension.

2. To find out CSF opening pressure by lumbar puncture and manometry.

3. To correlate CSF opening pressure with ONSD

4. To measure optic nerve sheath diameter after lumbar puncture and to find out changes in ONSD following CSF drainage.

\section{Secondary Objectives}

1. To compare ONSD in test and control groups

2. To find optimal ONSD cut off which will identify IIH

3. To study changes in optic nerve sheath diameter 6 months after CSF drainage in patients with idiopathic intracranial hypertension.

\section{Methodology}

Study Design: Prospective observational study.

Study Setting: Department of Neurology, Government Medical College, Thiruvananthapuram.

Study Subjects: Patients who are diagnosed to have IIH

Inclusion Criteria: Patients in the age group 12 and above who are clinically diagnosed to have $\mathrm{IIH}$ according to modified Dandy criteria
1. Signs and symptoms of the increased intracranial pressure (headache, nausea, vomiting, transient visual obscurations or papilledema)

2. Absence of focal neurological symptoms (except for abducens nerve palsy).

3. Cerebrospinal fluid opening pressure increase $>250 \mathrm{~mm} \mathrm{H} 2 \mathrm{O}$

4. Normal composition of cerebrospinal fluid.

5. Normal CT / MRI (including MR venogram)

6. No other reason for intracranial hypertension

\section{Exclusion Criteria:}

1. Patients who are having other causes for raised ICP

2. Patients who did not give a valid consent

\section{Sample Size and Sampling}

$$
\mathrm{N}=\left[\mathrm{Z}_{1-\beta}+\mathrm{Z}_{1-\alpha / 2}\right]^{2} /\left[\mathrm{R}^{2} /\left(1-\mathrm{R}^{2}\right)\right]=25
$$

R-Correlation coefficient $=0.5 \quad 161, \quad \mathrm{Z}=95 \%$ Confidence interval, $1-\alpha / 2=$ confidence limit, $\beta=$ power of study $=80 \%$

All diagnosed cases in the department of Neurology during the study period were included in the study. Total 30 cases were included in the study period. 30 age and sex matched asymptomatic persons were included as controls.

Duration of Study: April 2017 to July 2018

\section{Data Collection}

Institutional research committee and ethics committee approval were obtained.30 patients were included after getting informed consent.30 age and sex matched asymptomatic persons were included as control. Patients in whom IIH was suspected clinically were evaluated with MRI \& MRV to rule out secondary cause for raised ICP. Transorbital ultrasonography was done under guidance of neuroradiologist to measure ONSD. It was done using B mode ultrasound systemPHILIPS machine, and probe frequency of 7-12 MHZ was used. The probe is placed on the temporal part of the upper eyelid slightly superior to the upper corneal rim using a thick layer of ultrasound gel. ONSD was measured $3 \mathrm{~mm}$ behind lamina cribrosa as this area is more sensible to change in CSF pressure. Transorbital ultrasonography was done in 30 controls also. The ONSD is a hypoechoic strip extending from the back of the orbit. It is measured $3 \mathrm{~mm}$ from its insertion. The ocular nerve sheath diameter is marked in the diagram as solid arrows (B).

Diagnostic criteria for IIH- Modified Dandy criteria [8]: 


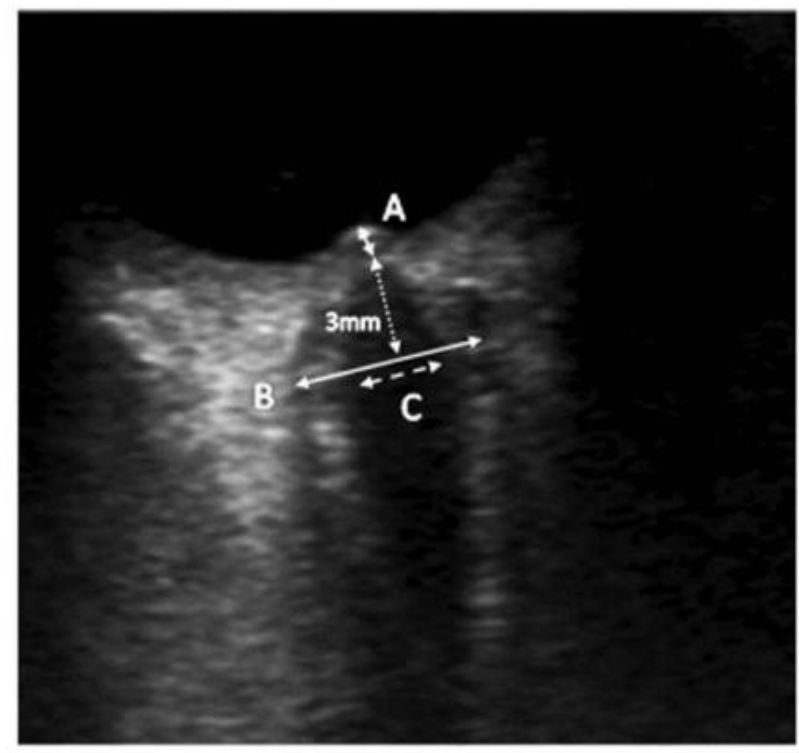

Fig-1: ONSD measurement using USG

\section{Lumbar Puncture}

Lumbar puncture was performed to find the CSF opening pressure and CSF analysis. The patient is asked to lie on her side, facing away from the examiner. The neck is gently anteflexed and the thighs pulled up toward the abdomen. LP was performed at or below the L3-L4 interspace. CSF opening pressure was measured using a manometer attached to lumbar puncture needle. The upper limit of normal opening pressure with the patient supine is $180 \mathrm{~mm}$ of CSF in adults. Therapeutic CSF drainage was done to normalize the CSF closing pressure. Transorbital sonography was repeated one hour after CSF drainage to assess the changes in ONSD following CSF drainage. Correlation between CSF opening pressure and ONSD was assessed. Patients were advised salt restriction, weight reduction and acetazolamide. They were kept under follow up. Follow up ONSD was done at 6 months.

\section{DAta ANALYSIS}

Data were entered into Microsoft Excel sheet. Analysis of data was done using statistical software SPSS 24. All continuous variables were tested for normality using Shapiro wilk test. Mean of normally distributed variables were compared using independent $\mathrm{t}$ test and non-normally distributed variables using Mann-Whitney U test. Chi square test was used to compare categorical variable and Fischer-Exact test was used when count inside a cell was $<5$. ROC curve was drawn to find the optimum cut off of ONSD that would predict raised CSF pressure. Optimum cut off was calculated using Youdens index. To find the correlation between two continuous variables, Pearsons test was used when variables were normally distributed and Spearman test was used when variables were not normally distributed. Difference between pairs of means was compared with paired t test when variables were normally distributed and with Wilcoxon signed Ranked test when variables were having non-normal distribution.

\section{Results}

A total of 60 subjects (30 cases and 30 controls) were included in the study. The baseline characteristics of the study population is shown in Table-1.

Table-1: Baseline characteristics of the study population

\begin{tabular}{|l|l|l|l|l|l|l|l|}
\hline & \multicolumn{3}{|l|}{ Case } & \multicolumn{2}{l|}{ Control } & df & p \\
\cline { 2 - 8 } & $\mathbf{N = 3 0}$ & $\mathbf{\%}$ & $\mathbf{N = 3 0}$ & $\mathbf{\%}$ & & & \\
\hline Age in years & & & & & & & \\
\hline$\leq 20$ & 3 & 10.0 & 3 & 10.0 & 2.533 & 3 & .469 \\
\hline $21-30$ & 13 & 43.3 & 17 & 56.7 & & & \\
\hline $31-40$ & 8 & 26.7 & 8 & 26.7 & & & \\
\hline$\geq 41$ & 6 & 20.0 & 2 & 6.7 & & & \\
\hline Gender & & & & & & & \\
\hline Male & 3 & 10.0 & 8 & 26.7 & 2.783 & 1 & .095 \\
\hline Female & 27 & 90.0 & 22 & 73.3 & & & \\
\hline BMI & & & & & & & \\
\hline Obese & 14 & 46.7 & 9 & 30.0 & 4.286 & 1 & .038 \\
\hline
\end{tabular}

Obesity was present in 14 patients $(46.6 \%)$ of patients having $\mathrm{IIH}$ and in $9(30 \%)$ of controls. 11 patients $(36.7 \%)$ were overweight. Mean BMI in test group was $29 \pm 3.4$. In control group it was $26.9 \pm 4.2$.
( $\mathrm{p}=0.36$, Mann-Whitney $\mathrm{U}$ test) and the difference was statistically significant. The comparision of symptoms between cases and controls is shown in table 2. CSF study and MRI findings are shown in Table-3. 
Table-2: Comparision of symptoms between case and control groups

\begin{tabular}{|l|l|l|l|l|l|l|l|}
\hline & \multicolumn{2}{|l|}{ Case } & \multicolumn{2}{l|}{ Control } & \multirow{2}{*}{$\chi \mathbf{2}$} & df & $\mathbf{p}$ \\
\cline { 2 - 9 } & $\mathbf{N}$ & $\mathbf{\%}$ & $\mathbf{N}$ & $\mathbf{\%}$ & & & \\
\hline Headache & 28 & 93.3 & 0 & 0.0 & 52.500 & 1 & $<0.001$ \\
\hline Blurring of vision & 21 & 70.0 & 0 & 0.0 & 32.308 & 1 & $<0.001$ \\
\hline Menstrual irregularities & 6 & 22.2 & 0 & 0.0 & 5.571 & 1 & .018 \\
\hline Recent weight gain & 4 & 13.3 & 0 & 0.0 & 4.286 & 1 & .038 \\
\hline Hypothyroidism & 5 & 16.7 & 0 & 0.0 & 5.455 & 1 & .020 \\
\hline Papilledema & 30 & 100.0 & 0 & 0.0 & $60.000 \mathrm{a}$ & 1 & $<0.001$ \\
\hline Sixth cranial nerve palsy & & & & & & & \\
\hline Bilateral & 7 & 23.3 & 0 & 0.0 & 30.000 & 2 & $<0.001$ \\
\hline Unilateral & 13 & 43.3 & 0 & 0.0 & & & \\
\hline
\end{tabular}

Table-3: CSF and MRI findings

\begin{tabular}{|l|l|}
\hline Investigations & \\
\hline Mean CSF opening pressure (mm of CSF) & $343 \pm 96$ \\
\hline Mean CSF protein (mg/dl) & $24 \pm 8$ \\
\hline MRI Findings & \\
\hline Partial empty sella & $50 \%$ \\
\hline Complete empty sella & $13.3 \%$ \\
\hline Buckling of optic nerve & $23.3 \%$ \\
\hline Slit like ventricles & $23.3 \%$ \\
\hline Left transverse sinus stenosis & $40 \%$ \\
\hline
\end{tabular}

Table-4: ONSD measurements

\begin{tabular}{|l|l|l|l|l|l|l|l|}
\hline $\begin{array}{l}\text { ONSD } \\
(\mathbf{m m})\end{array}$ & $\begin{array}{l}\text { Case (Mean } \\
\pm \mathrm{SD})\end{array}$ & $\begin{array}{l}\text { Control } \\
(\text { Mean } \pm \text { SD) }\end{array}$ & $\mathbf{p}$ value & Paired comparison & \multicolumn{2}{|l|}{$\begin{array}{l}\text { Paired } \\
\text { Differences }\end{array}$} & \multirow{2}{*}{ Paired t test p } \\
\cline { 5 - 8 } & & $4.93 \pm 0.26$ & & & & & \\
& & & & Opening VS closing & 0.6 & 0.4 & $<0.001$ \\
\hline Pre LP & $6.46 \pm 0.67$ & & $\begin{array}{l}\mathrm{p}<0.001, \\
\mathrm{t}=9.05\end{array}$ & & & & \\
\hline Post LP & $5.83 \pm 0.48$ & & & $\begin{array}{l}\text { Opening VS 6 months } \\
\text { follow-up }\end{array}$ & 1.3 & 0.6 & $<0.001$ \\
\hline $\begin{array}{l}6 \\
\text { f months } \\
\text { follow up }\end{array}$ & $5.18 \pm 0.58$ & & & & & & \\
\hline
\end{tabular}

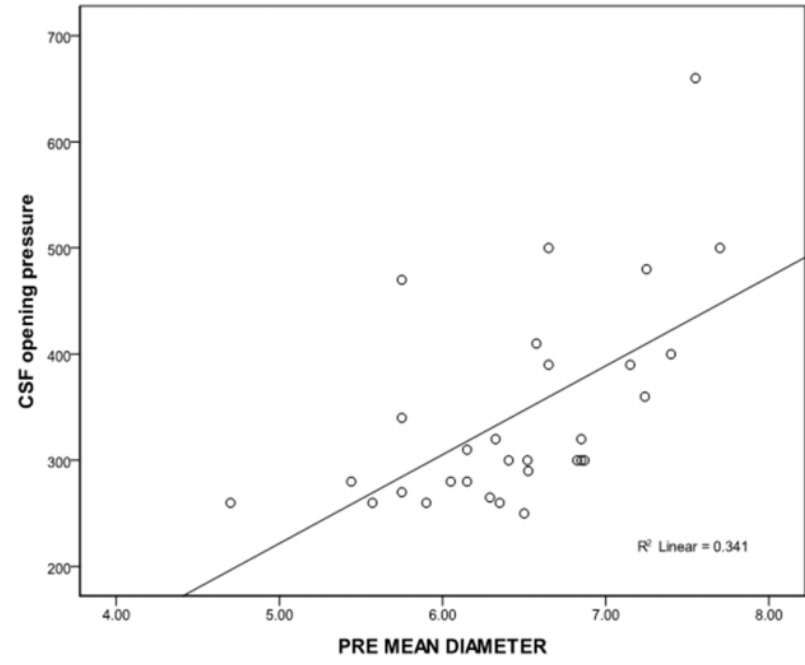

Fig-2: Scatter plot showing the correlation between ONSD before LP and CSF opening pressure

The correlation coefficient between mean CSF opening pressure and ONSD was found as $\mathrm{R}=0.584$, $\mathrm{p}<0.001$. There was strong correlation between mean CSF opening pressure and ONSD.

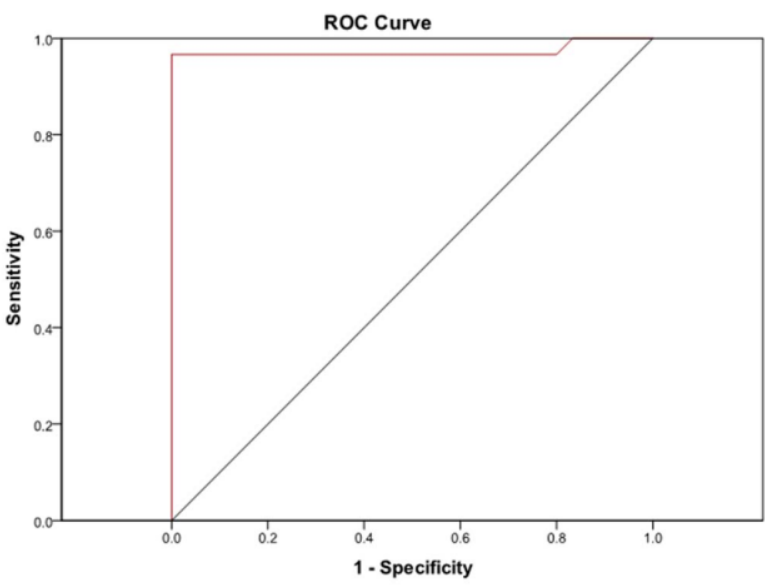

Fig-3: ROC curve of mean ONSD before LP and CSF opening pressure

To find the optimum ONSD which will correctly predict IIH, ROC curve was plotted. Area under the curve was $0.973, \mathrm{p}<0.001$. Optimum ONSD 
to detect increased CSF pressure and to diagnose IIH was $5.42 \mathrm{~mm}$ with sensitivity and specificity of $96.7 \%$, positive predictive value was $96.7 \%$ and negative predictive value was $96.7 \%$.

\section{DiscuSSION}

The study was conducted in patients admitted in Neurology ward, Government Medical College, Thiruvananthapuram. In this study, 30 patients with IIH were studied. 30 people without any neurological disorders also underwent ultrasonographic ONSD measurement. Among patients having IIH, mean age of onset was $30.6 \pm 9.2$ years. In the study by Durcan et al., $59 \%$ of patients were in the third decade of life at diagnosis [9]. In the study conducted by Radhakrishnan et al., and mean ages at onset was 28 years [10]. It was 29 years in the study by Craig et al., and 31 years in the study by Wall and George $[11,12]$. So, the mean age of onset in the present study was similar as that in other published studies. Among patients having IIH, 90\% were females. Female to male ratio was 9:1. This is similar to reported female to male ratios from larger studies. It was $8: 1$ in the study by Kesler et al., and 9.3:1 in the study by Galvin and Van Stavern in 2004 $[13,14]$. Obesity was present in $46.6 \%$ of patients having IIH. Published rates of obesity in patients with IIH include $71 \%$ in the study by Radhakrishnan et al., $88 \%$ in the study by Galvin and Van Stavern in 2004 and $91 \%$ in the study by Kesler and Gadoth, in 2001 $[10,13,14]$. A recent case-control study done in US by Daniels et al., reported that patients who are overweight also had an increased risk of IIH [15]. In this study, 11 patients having IIH $(36.7 \%)$ were overweight. Recent weight gain was present in 4 patients $(13.3 \%)$. None of the controls had recent weight gain and the difference was significant. Study by Radhakrishnan et al., reported that recent gain in weight as such is a risk factor for IIH [10].

Menstrual irregularities were present in 6 $(22.2 \%)$ cases. This finding is similar to the study conducted by Ireland et al., in which menstrual irregularities were more in patients having IIH. Studies conducted by Glueck et al., also have listed menstrual dysfunction amongst reported symptoms [16].

History of drug intake was present in 8 $(26.6 \%)$ patients having IIH. Five among them were taking thyroxin for hypothyroidism and three were taking oral contraceptive pills. Oral contraceptive pills are proven to be a risk factor for IIH. The study by Glueck et al., reported a series of 65 women with IIH in which $24(37 \%)$ were taking oral contraceptive or exogenous estrogens [16]. Hannah Massey et al 168 reported a case of IIH associated with levothyroxine therapy [17]. Total 11 such cases are reported in literature till now. Headache was the most common presenting symptom. Headache was present in 23 patients $(93.3 \%)$. This is similar to the finding in studies by Wall and George, Radhakrishnan et al., and Kesler and Gadoth [10, 12, 13]. In these studies, headache was the most common presenting symptom and occurrence varied from $68 \%$ to $98 \%$ of patients having IIH.

Blurring of vision was the next common presenting symptom which was present in 21 (70\%) cases. This is similar to the studies by Galvin and Van Stavern, in which blurred vision was the second common manifestation [14]. Other studies like studies by Wall and George, Radhakrishnan et al. and Kesler and Gadoth also reported similar findings [10, 12, 13].

Papilledema was present in all cases.6th Cranial nerve palsy was present in $66.6 \%$ of patients, it was bilateral in $23.3 \%$, unilateral in $43.3 \%$. None of the controls had cranial nerve palsy. As per diagnostic criteria of IIH, there should not be any focal neurological deficit. But unilateral or bilateral 6th cranial nerve palsy is expected secondary to raised intracranial pressure. Previous studies by Corbett et al., Radhakrishnan et al., and Mezaal and Saadah reported unilateral or bilateral 6th cranial nerve palsy and occurrence varied from $17 \%$ to $33 \%$ in those studies $[10,17,18]$.

Mean CSF opening pressure was $343 \pm 96 \mathrm{~mm}$ of CSF. This was similar to the finding in the study by Corbett and Mehta where the average CSF pressure was $344 \mathrm{~mm}$ of CSF. Mean CSF protein was $24 \pm 8$. In the study by Chandra et al., it was reported that CSF protein level may be less than normal in patients with IIH [19].

In MRI findings, partial empty sella was present in 15 cases $(50 \%)$, complete empty sella in 4 cases $(13.3 \%)$, buckling of optic nerve in $7(23.3 \%)$ and slit like ventricles in 7 (23.3\%). In MRV, left transverse sinus stenosis was present in in 12 cases (40\%). These findings were similar to the findings of Brodsky and Vaphiades who reported that vertical tortuosity of the orbital optic nerves and empty sella are specific markers of raised intracranial pressure in patients having $\mathrm{IIH}$ [20].

Mean ONSD in control group was $4.93 \pm 0.26$ $\mathrm{mm}$. In patients with IIH, mean ONSD before LP was $6.46 \pm 0.67 \mathrm{~mm}$, after LP, mean ONSD was $5.83 \pm$ 0.48 . These findings were similar to the findings from the study conducted by Jochen Bauerle et al., in 25 patients in Germany showed that subjects with $\mathrm{IIH}$ showed mean ONSD of $6.4 \pm 0.6 \mathrm{~mm}$ [21]. In controls, the mean ONSD was $5.4 \pm 0.5$. Another multicentric study done in 21 patients by Piergiorgio Lochner et al., shown that ONSD values were significantly higher in patients with IIH, mean being $6.50 \pm 0.67 \mathrm{~mm}$. In control group mean was $5.73 \pm 0.66 \mathrm{~mm}$ [22]. Another study from Pakistan by Hina Rehman et al., done in 26 patients also shown similar findings with mean ONSD $6.61 \pm 0.39 \mathrm{~mm}$ in patients with IIH and $4.33 \pm 0.38 \mathrm{~mm}$ in controls [23]. 
There was positive correlation between mean CSF opening pressure and ONSD. This finding was similar to the findings of the study done by Pablo del SazSaucedo et al., which also showed a positive correlation [24]. But the study by Piergiorgio Lochner et al., failed to show a correlation between ONSD and CSF opening pressure [22].

There was statistically significant reduction in ONSD following CSF drainage. This finding was also similar to the study results of Pablo del Saz-Saucedo et al., [24] In this study optimum ONSD to detect increased CSF pressure and to diagnose IIH was 5.42 $\mathrm{mm}$ with sensitivity and specificity of $96.7 \%$, positive predictive value was $96.7 \%$ and negative predictive value was $96.7 \%$. This finding is similar to the results of study conducted by Jochen Bauerle et al., which reported the best cut-off value of ONSD for detecting raised ICP was $5.8 \mathrm{~mm}$ with a sensitivity of $90 \%$ and a specificity of $84 \%$ [21]. The study by Pablo del SazSaucedo et al., showed the best cutoff point for detecting raised ICP was $6.3 \mathrm{mms}$, with a sensitivity and specificity of $94.7 \%$ and $90.9 \%$ respectively [24]. This study got a higher cut off of ONSD compared to present study and study by Jochen Bauerle et al., [21] The author concluded it could be due to interobserver variation. At 6 months follow up, mean ONSD was 5.18 \pm 0.58 . This change was statistically significant when compared with mean ONSD before LP. This indicated the response to treatment i.e., the reduction in CSF pressure in response to $\mathrm{CSF}$ drainage and medical treatment.

\section{Conclusions}

- CSF opening pressure and optic nerve sheath diameter are having positive correlation, $\mathrm{r}=0.584, \mathrm{p}<0.001$

- Optimum value of ONSD to predict IIH is 5.42 $\mathrm{mm}$ with sensitivity and specificity of $96.7 \%$.

- There was significant reduction in ONSD following LP and CSF drainage, $\mathrm{p}<0.001$

- 6 months follow up showed significant reduction in ONSD on treatment with acetazolamide, salt restriction and weight reduction.

- Hence sonographic ONSD measurement can be used as a noninvasive method to diagnose and to follow up IIH patients.

\section{REFERENCES}

1. Dubourg J, Javouhey E, Geeraerts T, Messerer M, Kassai B. Ultrasonography of optic nerve sheath diameter for detection of raised intracranial pressure: a systematic review and meta-analysis. Intensive Care Medicine. 2011 Jul 1; 37(7):105968.

2. Moretti R, Pizzi B. Ultrasonography of the optic nerve in neurocritically ill patients. Acta
Anaesthesiologica Scandinavica. 2011 Jul 1; 55(6):644-52.

3. Galetta S, Byrne SF, Smith JL. Echographic correlation of optic nerve sheath size and cerebrospinal fluid pressure. J Clin Neuroophthalmol. 1989 Jun; 9(2):79-82.

4. Hassen GW, Nazeer O, Manizate F, Patel N, Kalantari H. The role of bedside ultrasound in pretherapeutic and posttherapeutic lumbar puncture in patient with idiopathic intracranial hypertension. The American Journal of Emergency Medicine. 2014 Oct 1;32(10):1298-e3.

5. Lee SH, Choi H, Koh SH, Lee KY, Lee YJ. MRI and ultrasonographic findings in idiopathic intracranial hypertension. Cephalalgia. 2013 Jan 1; 33(2):139-40.

6. Lochner P, Nardone R, Tezzon F, Coppo L, Brigo F. Optic Nerve Sonography to Monitor Treatment Efficacy in Idiopathic Intracranial Hypertension: A Case Report. Journal of Neuroimaging. 2013 Oct 1;23(4):533-4.

7. Singleton J, Dagan A, Edlow JA, Hoffmann B. Real-time optic nerve sheath diameter reduction measured with bedside ultrasound after therapeutic lumbar puncture in a patient with idiopathic intracranial hypertension. Am J Emerg Med. 2015; 33(6):860.e5-7.

8. Dandy, W. E. Intracranial pressure without brain tumor. Diagnosis and treatment. Annals of Surgery 1937; 106: 492-513.

9. Durcan FJ, Corbett JJ, Wall M. The incidence of pseudotumor cerebri: population studies in Iowa and Louisiana. Archives of Neurology. 1988 Aug $1 ; 45(8): 875-7$.

10. Radhakrishnan K, Thacker AK, Bohlaga NH, Maloo JC, Gerryo SE. Epidemiology of idiopathic intracranial hypertension: a prospective and casecontrol study. Journal of the neurological sciences. 1993 May 1; 116(1):18-28.

11. Craig JJ, Mulholland DA, Gibson JM. Idiopathic intracranial hypertension; incidence, presenting features and outcome in Northern Ireland (19911995). The Ulster medical journal. 2001 May; 70(1):31.

12. Wall M, George D. Idiopathic intracranial hypertension: a prospective study of 50 patients. Brain. 1991 Feb 1; 114(1):155-80.

13. Kesler A, Ellis MH, Reshef T, Kott E, Gadoth N. Idiopathic intracranial hypertension and anticardiolipin antibodies. Journal of Neurology, Neurosurgery \& Psychiatry. 2000 Mar 1; 68(3):379-80.

14. Galvin JA, Van Stavern GP. Clinical characterization of idiopathic intracranial hypertension at the Detroit Medical Center. Journal of the Neurological Sciences. 2004 Aug 30; 223(2):157-60.

15. Daniels AB, Liu GT, Volpe NJ, Galetta SL, Moster ML, Newman NJ, Biousse V, Lee AG, Wall M, Kardon R, Acierno MD. Profiles of 
obesity, weight gain, and quality of life in idiopathic intracranial hypertension (pseudotumor cerebri). American journal of ophthalmology. 2007 Apr 1; 143(4):635-41.

16. Glueck CJ, Aregawi D, Goldenberg N, Golnik KC, Sieve L, Wang P. Idiopathic intracranial hypertension, polycystic-ovary syndrome, and thrombophilia. Journal of Laboratory and Clinical Medicine. 2005 Feb 1; 145(2):72-82.

17. Massey H, Hoh YS, Rajesh A, Krishnakumar D, Goonetilleke R. Levothyroxine therapy associated with idiopathic intracranial hypertension (IIH). In BioScientifica; 2016 [cited 2018 Dec 9]. Available from: https://www.endocrineabstracts.org/ea/0045/ea0045p73

18. Corbett JJ, Mehta MP. Cerebrospinal fluid pressure in normal obese subjects and patients with pseudotumor cerebri. Neurology. 1983; 33(10):1386-8.

19. Chandra V, Bellur SN, Anderson RJ. Low CSF protein concentration in idiopathic pseudotumor cerebri. Ann Neurol. 1986 Jan; 19(1):80-2.
20. Brodsky MC, Vaphiades M. Magnetic resonance imaging in pseudotumor cerebri. Ophthalmology. 1998 Sep 1; 105(9):1686-93.

21. Bäuerle J, Nedelmann M. Sonographic assessment of the optic nerve sheath in idiopathic intracranial hypertension. Journal of neurology. 2011 Nov 1; 258(11):2014-9.

22. Lochner P, Brigo F, Zedde ML, Sanguigni S, Coppo L, Nardone R, Naldi A, Sola D, Stolz E. Feasibility and usefulness of ultrasonography in idiopathic intracranial hypertension or secondary intracranial hypertension. BMC neurology. 2016 Dec; 16(1):85.

23. Normal II. Optic nerve sheath diameter on sonography in idiopathic intracranial hypertension versus normal. Journal of the College of Physicians and Surgeons Pakistan. 2016; 26(9):758-60.

24. del Saz-Saucedo P, Redondo-González O, MateuMateu Á, Huertas-Arroyo R, García-Ruiz R, Botia-Paniagua E. Sonographic assessment of the optic nerve sheath diameter in the diagnosis of idiopathic intracranial hypertension. Journal of the neurological sciences. 2016 Feb 15; 361:122-7. 